\title{
USING OER AS A TOOL FOR AGRIBUSINESS MANAGEMENT TRAINING FOR HARD-TO- REACH RURAL FARMER POPULATIONS
}

\author{
Maina Muniafu, PhD \\ School of Science and Technology, USIU \\ Francis Wambalaba, PhD \\ Chandaria School of Business, USIU \\ Walter Wanyama \\ School of Science and Technology, USIU \\ Gidraph Nduati \\ School of Science and Technology, USIU \\ Dalton Ndirangu \\ School of Science and Technology, USIU
}

\begin{abstract}
Agriculture is the mainstay of Kenya's economy and contributes significantly to the gross domestic product. A great majority of this contribution comes from smallholder farmers who paradoxically face numerous obstacles ranging from a lack of support structures to poor policies and inadequate resources. A major challenge is assisting these farmers with making improvements in their production ventures, with the recently devolved form of government in Kenya enabling any assistance to be concentrated at a much lower and specific level within established counties. The United States International University (USIU) has been involved in the development of training materials for farmers and farmer organizations, specifically a course module based on several interdisciplinary field case studies. This farmers' agribusiness training course was developed on an open educational resource (OER) platform to help both farmers, who had limited training in commercialization of agriculture, and farmer organizations. The intention of the course was to provide access to additional skills and knowledge, allowing farmers to move from a farm to a "firm." Five farmers were identified from various parts of the country and participated in partnership with USIU faculty to develop the modules for the course over a one-year period. In order to complete these modules with the farmers, project staff frequently followed up with the farmers via field trips. The farmers provided positive feedback on the OER materials despite some challenges, such as the need for participants to be computer literate in order to utilize the materials directly. However, mobile learning presents an opportunity to address this shortcoming. Kenya has witnessed tremendous growth in the use of mobile phones in the rural population whose main occupation is agriculture. Although a few farmers were found to already be using a mobile SMS service to seek recommendations from the Ministry of Agriculture on the best agriculture practices and produce marketing, there is a need to establish whether mobile technologies can enhance farmers' training and support in the rural communities.
\end{abstract}

\section{KEYWORDS}


Using OER as a Tool for Agribusiness Management Training

for Hard-to-reach Rural Farmer Populations

Agribusiness, open educational resources, Kenya, AgShare, agriculture smallholder entrepreneurship

\section{INTRODUCTION}

\section{A. Agriculture in Kenya}

Agriculture is the mainstay of the Kenyan economy, directly contributing $26 \%$ and indirectly contributing another $25 \%$ of the gross domestic product annually. The sector accounts for $65 \%$ of Kenya's total exports and provides more than $70 \%$ of informal employment in the rural areas. Therefore, the agricultural sector is not only the driver of Kenya's economy, but also the means of livelihood for the majority of Kenyan people [2]. A major drawback, however (in terms of global scale), is the subsistence nature of production.

Firstly, as with many other sub-Saharan countries, a large majority of those involved in agriculture are small-scale farmers and production is carried out on farms averaging 0.2-3.0 ha, on a mixed subsistence/commercial basis. This small-scale production accounts for $75 \%$ of the total agricultural output and $70 \%$ of marketed agricultural produce. Small-scale farmers produce over $70 \%$ of maize, $65 \%$ of coffee, $50 \%$ of tea, $80 \%$ of milk, $85 \%$ of fish, and $70 \%$ of beef and beef-related products for output in Kenyan and external markets.

A huge potential exists to increase productivity for these farmers with the adoption of modern farming practices [2]. Adoption of improved inputs such as hybrid seeds, concentrated feeds, fertilizer, and safe uses of pesticides and machinery by small-scale farmers is relatively low. Farmers continue to rely on rain-fed production. This practice is in itself a severely limiting factor before considering other factors such as poor soils, pests, diseases, and recurrent drought.

Secondly, despite the presence of high-profile government ministries, government parastatals, and donor support, the grassroots farmer also suffers from a dire lack of support. Part of the support challenges came from the liberalization of the agricultural sector during the late 1980s. For example, limited investments in irrigation exist, and there is a lack of affordable technology to improve soil fertility, to control pests and diseases, to manage weeds, and to introduce drought-tolerant crop varieties. On top of all this, farmers have limited access to capital and infrastructure, including roads, railways, airports, and seaports, thus causing high transportation costs.

Thirdly, Kenya has undergone great demographic changes over the past half-decade with an eight-fold increase in population, having dramatic implications on landholding sizes, resource degradation and availability, and market availability for products, especially given the higher urbanization percentages. It is indeed questionable whether policy has developed in tandem with these changes. A unique feature of Kenya (unlike other sub-Saharan countries) is that all types of farmers, including poor, rich, large-scale, and smallholder farmers, participate in high-value agriculture products. Smallholder farmers, for example, produce $60 \%$ of all exported vegetables and fruits. These products, together with the traditional ones, have had a huge impact on the country's economy through income flow into rural economies, increased market efficiencies, strengthened domestic supply chains, increased provision of employment opportunities, and improved institutional development. However, in the face of market liberalization in the agricultural sector, its overall performance has not been encouraging, with stagnation and even falling agricultural incomes. Much agricultural policy research, training, and advocacy work remains the responsibility of and relies on the involvement of all stakeholders, so that everyone involved in agriculture will be better off in the liberalized environment. Kenyan agriculture will hence be able to be efficient enough to compete at world prices or at the levels of protection that domestic consumers or the world trade organization allow.

\section{B. Agricultural Extension Services}


Over time, the government has provided advice and services to farmers in what is termed extension services, with the ministry in charge of agriculture playing a leading role. Kenya's smallholder farmers have traditionally benefited first from the government extension system and second from a commoditybased system run by government parastatals, out-grower companies, and cooperatives. The first system focuses mainly on food crops and livestock, including several models such as the progressive (or model) farmer approach, the farming systems approach, and the integrated agricultural rural development approach. They also provide farm management models, training and visits, attachment of officers to organizations, and farmer field schools. The second system deals mainly, but not exclusively, with commercial crops such as coffee, tea, pyrethrum, and sisal. This system is consciously motivated by profits, and it tends to work well when both the firm and farmers clearly benefit from the extension expenditures. All aspects of producing and marketing a particular commercial crop are tightly vertically coordinated, spanning the whole range from research, advice, and material support given to farmers in order to organize marketing and even exports [3]. But it is the lack of success of both of these extension service models that has given rise to private extension services from non-governmental organizations (NGOs), community-based organizations, and faith-based organizations [4]. Private extension services also give academic institutions, such as USIU, room to work with the farmers and farmer-based organizations.

\section{DEVELOPMENT OF THE AGRIBUSINESS MANAGEMENT MODULES FOR FARMER ORGANIZATIONS}

The development of the agribusiness management modules was based on several interdisciplinary field case studies, along with the provision of consultancy services to participating farmers as part of the AgShare open education resource (OER) project. The purpose of the study was to develop a pedagogical model and a pilot module for teaching farmer organizations, such as community-based organizations, to change their attitude, gain new knowledge, and acquire agribusiness-management skills for transforming farming from a livelihood practice to a business enterprise; in other words, transforming the farmer's mindset to perceive a farm as a firm. The project involved research and consulting activities to cultivate a process of learning among all the three key stakeholders: faculty, students, and farmers. The project developed a pilot course module by combining concepts with regard to the structure of the agricultural sector and policies, context of the economics of a firm, behaviors of an entrepreneurial mind set, sustainable farming, and applications of information technology. The framework was based on five key outcome objectives as outlined below.

1. Form community-wide partnerships: The goal here was to enable and facilitate community-wide partnerships, networking opportunities to support the project's vision, and an exploration of policy and strategy issues. These activities included partnerships with both farmer organizations and other relevant stakeholders (such as partnerships among USIU faculty and at least one university in Kenya with agriculture faculty), one producer organization, and one NGO involved in women's rights and agricultural/rural development. The intent was to create arrangements for feedback loops among those partners for information sharing for OER development and use and re-use.

2. Build capacity: The framework was tailored to facilitate advanced business-management and organizational-skill development in farmers and producer organizations to increase their overall ability to transform members' farming practices into a business enterprise. Similarly, in partnership with a local agriculture university (an AgShare partner), the module was to be used for training master's-level students as a fieldwork seminar. This module included creating capacity for awareness of OER platforms, an understanding of packaging information, and using and re-using OER materials among all USIU AgShare project partners. 
3. Create learning materials: The team worked in partnerships with Moi University to co-create an OER environment and associated learning materials. USIU faculty developed syllabus content, teaching and class activity content, and case studies for teaching. They also taught the course in collaboration with each other from an interdisciplinary perspective. USIU internship students participated in the module development and case-study process. They developed case study scenarios through interviewing and data collection, writing farmer stories, and capturing farmer experiences through film and pictures. The completed draft was shared with the AgShare partner universities for feedback, input, and possible adoption. All USIU AgShare project partners agreed on open access licensing of AgShare project materials. This was a noncredit module except that participants were to receive a certificate of completion.

4. Create an AgShare fellows program: The AgShare fellows program consisted of farmers, faculty, and students who championed the concept of OER within their respective universities. USIU coordinated with internship and community service programs to recruit student AgShare fellows who would capture local stories that could be used as illustrations, examples, and even case studies. Four students were recruited, including three USIU undergraduate students from journalism, entrepreneurship, and IT, as well as one agriculture master's student from the AgShare partner university.

5. Assess the impact: During phase two of the project, the team embarked on project assessment with the dual quantitative and qualitative goals of determining the level of output, as well as the effects of the project. The output levels included assessing the level of partnership and networking; developing modules for farmer organizations; and generating a variety of OER materials (modules, cases, and video). Determination of impacts included the effect on farmers, the effect on faculty and students, and the desirability of using modules at universities.

Issues of sustainability and ethics were embedded in the modules. Agribusiness issues included green business development, sustainable supply chains, and a focus on the development of socially responsible ventures. The farmer organization issues also included concepts of green farming practices, carbon footprint minimization, economically sustainable planting and harvests methodologies, and sustainable and just labor practices. These issues and concerns were included through participating faculty's selection of appropriate books, articles, case studies, experiential exercises, and facilitated discussions and lectures that make reference to sustainability and ethics or provide a format for use as an analytical tool.

\section{ASSESSMENT OF OER IMPACT ON FARMERS}

USIU worked to develop the modules with six farm communities in the regions of Athi River, Mwingi, Emali, Limuru, Nakuru, and Kapsabet. Each community was distinct in its history, purpose, and function. While USIU worked with those who were appointed by the groups or individuals considered change agents in the communities, the total number of farmers among all of those communities was nearly 10,000. The assessment varied amongst the groups. Some farmers participated in surveys, and in at least two cases, indepth interviews were done with those farmers who were most engaged in the project.

The nature and extent to which the farmers got involved with the university's training program and employed the OER materials grew over time. They started off by providing information to faculty to develop case studies; afterwards, the farmers were provided with training on how to practice commercial farming as opposed to subsistence farming. Over time, the farmers managed to access farming and managerial information in terms of decision making regarding best farming practices, current farming trends, and finally, the feasibility of farming as a firm.

The farmers agreed that the project team surpassed their expectations because of the knowledge the farmers gained. After reviewing the OER site and understanding that the information there is being 
accessed worldwide, they were astonished to learn that the information they provided is also viewed all over the world, thus confirming that the training program has stretched far beyond their expectations. The farmers were able to learn a lot from the different modules and developed a clear understanding of the myriad of concepts that had been put forth in the program. They also understood what lacked in the production units and the way forward in making improvements. The farmers were also exposed to farming methods that differed from their own by interactions with other farmers. For example, animal husbandry was introduced to those practicing crop farming and vice versa. In terms of treating farming as a firm and not just a farm, this mindset empowered women to be able to develop some form of income through farming practices; therefore enabling them to also open bank accounts, access bank loans, and gain knowledge, especially about computers and farming information, to name only a few examples. The farmers felt involved in the development of case studies, which had a positive impact on them because they felt relevant and that their views mattered. It was opportunity for them to showcase their abilities and monitor their own progress.

It was also noted that the OER program materials were a huge help, since government websites were not up-to-date on different farming methods. These OER materials have changed the way farmers run their farms, including the formation of support groups. Some farmers realized that individually, they may not be recognized. But as a group, not only can they can be registered, but they can also share information and ideas. A further positive element in achieving a farm-to-firm mindset was the farmers' ability to structure their farming methods and increase their record keeping. The farmers made the changes with the AgShare team's guidance and constant communication in the learning process.

According to the USIU, farmers gained meaningful knowledge from the following AgShare modules:

- Module 1: Structure of Agricultural Sector and Policies

- Module 2: Agribusiness Management For Farmer Organization

- Module 3: Entrepreneurship Mindset

- Module 4: Information and Communication Technologies (ICT) in Support of Agriculture

- Module 5: Sustainable Agriculture

The project involved students who were able to follow up on the farmers since their involvement in the AgShare project. The following are some of the key highlights regarding their post-project efforts with information technology:

- The evaluation results indicate that $75 \%$ of the farmers have invested in new ventures, including silage development, fish aquaculture projects, milk storage, generator and track shredder acquisitions, M-PESA (a mobile money-transfer solution), and motorbike transportation. Of the remaining $25 \%$ of farmers, $16.7 \%$ are in the process of investing in new ventures, while $8.3 \%$ have not invested in any new venture. For new ventures, sources of funding for these investments include the nonprofit organization, TechnoServe; the Ministry of Agriculture; banks; and farmers' personal savings.

- None of the farmers has visited the AgShare OER website after the project, mainly due to lack of computers and accessibility to the Internet.

- Communication has been maintained with farmers through farm visits, use of media, meetings during collection center morning deliveries, vernacular radio stations, television, workshops, seminars, exchange programs and practical sessions, churches, bulletins at county authority offices, information sharing during "harambees," and schools. It can be noted that the communication involves a personal involvement of the program developers (faculty) along with other stakeholders who can bring about change beyond simply posting information on websites. From the university's perspective, it was important to quantify what the benefits were.

The studies conducted during farm visits and data collection equipped the students with relevant skills and knowledge for future studies in related fields and provided a good avenue for exposure to the real- 
world farming situation. The students' attitudes towards farming had a positive change, and they gained more interest in the industry. Working as a team with the farmers helped empower the students as they gained more confidence in their work and their expertise.

The faculty gained an appreciation of open source learning and are keener on information packaging for students. The interaction with farmers and the diversified collaborative work helped the faculty learn more from farmers and appreciate groundwork.

This collaboration is likely to continue since all faculty were willing to share their expertise and recognized for their input.

The AgShare stakeholders' workshop took place at the United States International University. The main objectives of the workshop included the following:

1. Establish the relevance of the materials developed by the AgShare faculty of USIU, in essence covering all aspects of modern day agricultural principles and practices.

2. Determine the areas of collaboration by the stakeholders with regard to using the materials and incorporating them into the faculty's respective institutions and organizations.

3. Ascertain the adaptability of the materials in the field of agriculture, especially when addressing agriculture in a developing country where many factors come into play; e.g., cultural dynamics, illiteracy, and an ever-changing technological world.

\section{RECOMMENDATIONS}

Both teams of stakeholders highly praised the materials and had a variety of recommendations for multiple areas of collaboration.

1. The Ministry of Agriculture, represented by the Head of Trade Promotion, Mrs. Annastacia Kiio, proposed that the materials be included by the government on the Kilimo website for their promotion of the use of e-agriculture.

2. Moi University wished to incorporate the materials in their CMAAE master's program as a graduate student tool for research and outreach delegation, which would be led by Professor Mark Odhiambo.

a. The university commended the materials for covering core aspects of day-to-day agricultural business in modern life, from learning about governmental policies to the economics of a firm in order to sustain output. The entrepreneurial perspective was believed to incorporate information technology in a way that would allow farmers to carry out a sustainable farming practice.

b. The materials were deemed relevant and the review was productive.

Based on the interactions with faculty, students, and farmers, the USIU team is recommending the following improvements for the AgShare project.

1. Materials are to be translated into the national language, Kiswahili, and/or a mother tongue for the sake of the farmers who are not literate in English. This translation could also be extended to other national languages.

2. The team requires training support in order to convince other farmers to take advantage of the AgShare materials on the OER site.

3. Donations of more computers and computer training packages are needed. Regarding site maintenance, monthly website content updates and journal articles available for download are to be included. More pictorial demonstration will be developed and wording will be reduced.

4. Audio tapes will be distributed to farmers, along with a training manual/handbook.

5. More emphasis should be placed on ICT in agriculture as this will not only help the farmers to obtain information from the Internet, but it will also open them up to a large pool of knowledge available on the World Wide Web. This access calls for intense periodic training and the likely establishment of computer hubs at selected trading centers and market towns. 
6. More videos will be developed that focus on showcasing the improvements implemented by other farmers, which will create exposure for them and establish a potential farmer exchange program. For example, farmers in South Africa could send videos on their practices to farmers in Kenya and vice versa. It would also be an interactive platform in the exchange of ideas.

7. Scheduled visitations and exchange programs amongst the farmers are to be emphasized so that farmers can learn from one another in person. For example, the farmers from Bungoma will be sent to visit farmers in Tigania in June and July.

8. AgShare should open main resource centers in different strategic areas and have a contact person who will have access to firsthand information, relaying it to the AgShare farmers and faculty.

\section{EXPANDING THE REACH OF AGRIBUSINESS MANAGEMENT MODULES}

One challenge of the developed modules is that farmers need to be computer literate and also have access to computers. While no data is available on computer literacy, it is safe to state that the literacy levels are higher in urban centers of Kenya, while levels will be low in rural areas, especially amongst the older generation of farmers who still are the majority. The emergence of new technologies has proven to be useful in many sectors such as business, healthcare, and agriculture. Information and communication technologies (ICT) can play an important role in addressing the challenges faced by community-based agricultural organizations. These challenges include the need to increase production to feed a growing and prosperous population as natural resources availability decreases (for example, decreases occur due to water shortages, declining soil fertility, effects of climate change, and a rapid decrease of fertile agricultural lands due to urbanization). Given all these challenges, the key participants in the country's agricultural production system (mainly the rural agricultural community) require attention, with an important role of organizations such as USIU and its partners to bring together both private sector and organized farming groups through a common ICT platform. A possible end result of this collaboration will be that the livelihoods of the rural poor may improve. This improvement may occur because emerging ICT solutions have the potential to strengthen the connections among community-based organizations in rural agricultural, including enhancing capacity building and empowerment to the communities, enhancing agricultural production, and improving market access and relevant agricultural information in Kenya. One example of ICT use can be through mobile phones. According to the Communication Commission of Kenya [1], mobile phone subscribers in the country increased to 22 million between July and September 2010, with affordability being the key to past and expected growth. This growth means that through central connectivity, farmer organizations can access information from the modules relevant to production process improvements. Although it was found that a few farmers have been using mobile short message services (SMS) to seek assistance on the best agriculture practice and marketing of farm produce, there is a need to establish whether other mobile technologies like mobile mapping can enhance the farmers' training and support. Such a study will seek to determine the need for mobile mapping technology as an alternative form of mobile support for rural populations. Local college students and agricultural government agents in their respective counties will be required to develop databases of agricultural best practices, policies, and marketing information of the locally produced goods. The database will be mapped and hosted in the respective county headquarters, and the results will be used by local farmers to improve agricultural activities. In this way, rural farmers will save travel time when seeking information and support regarding best practices. Local college students may develop a desire to work more in depth with farmers after participating in the development of the databases as well.

\section{CONCLUDING OBSERVATIONS}

The process of course development is in itself a research process that imparts learning experiences on developers, which are solidified by the consultancy outcome. These experiences are further enriched by not only a process of integrative learning, but also when the teacher, student, practitioner, and program 
participants work together to create knowledge, develop skills, and change attitudes through research and information exchange. For example, as farmers learned how to use the Internet as a tool, particularly for using AgShare OER materials, their farming methods were altered, especially with the introduction of computers. This process was a marked change from their experiences with agriculture-based NGOs and local government agencies. This project was thus a demonstration of the positive impact of the integrative and collaborative processes of learning. The assessment procedures also allowed for a measurement of the effectiveness of the module. Certainly, the enthusiasm of the farmers towards the material in the module served as an indicator of the need for packaging information in a way that is accessible to rural Kenya, the most effective platform likely exists through computer-based online programs, but given the current access challenges, mobile phone platforms may be an interim solution.

\section{REFERENCES}

1. Communications Commission of Kenya. Quarterly Sector Statistics Report, 1st Quarter (JulySept 2010/2011).http://www.cck.go.ke/news/2011/Mobile_subscribers.html

2. Agricultural Sector Development Strategy. Agricultural Sector Development Strategy, 20102020. Government of Kenya. (2010). www.kilimo.go.ke

3. Muyanga, M, and Jayne, T.S. Agricultural Extension in Kenya: Practice and Policy Lessons Working Paper 26 (2006). Tegemeo Institute of Agricultural Policy and Development, Egerton University, Njoro, Kenya.

4. Nambiro, E., Omiti, J., and Mugunieri, L. Decentralisation and Access to Agricultural Extension Services in Kenya. SAGA Working Paper (October 2005).

\section{ACKNOWLEDGEMENTS}

Professor Maina Muniafu would like to express utmost gratitude to all the authors: Professor Francis Wambalaba, Professor Gidraph Nduati, Professor Dalton Ndirangu, and Professor Walter Wanyama, who assisted with and have worked through the process of this article. The authors would like to thank Michigan State University and OER Africa, who found them to be worthy partners in the AgShare grant, which was generously funded by the Bill \& Melinda Gates Foundation. USIU's added entrepreneurial aspect to the AgShare program was a valued addition to the project's success.

Maina Muniafu, Francis Wambalaba, Gidraph Nduati, Walter Wanyama, Dalton Ndirangu, and Akosa Wambalaba are the module developers and case study research faculty at USIU. They were assisted by Mark Odhiambo of Moi University, a team of student interns, the Sustainable Development Initiatives Center (SUDIC) secretariat, OER Africa, and farmers from Emali, Kajiado, Kapsabet, Kiambu, Nakuru, Tigania, and Sikulu. The study was funded by Michigan State University's AgShare project. The team is greatly indebted to USIU, the farmers, and the students who offered a lot of invaluable support towards the completion of this project. The team would like to sincerely thank all respondents; they are truly grateful to you.

\section{ABOUT THE AUTHORS}

Maina Muniafu is an associate professor of natural sciences, and his specialty areas are sustainable utilization and development of resources and general environment sciences. He is in the School of Humanities and is the founding director of the Sustainable Development Initiatives Centre. He has been involved in both the AgShare and the Agribusiness programs, whereby he has shared his expertise on sustainable agriculture and global agricultural market place and fundamentals for exports/imports, respectively.

Francis Wambalaba is a professor of economics and deputy vice chancellor-Academic Affairs (Research), and his specialties are international economics, economic development, comparative 
economics, managerial economics, transportation economics, and planning and urban studies in regional structure.

Walter Wanyama is an assistant professor of information systems, and his specialty areas are information systems, information services, and management media technology and communication design. He worked together with Professor Dalton Ndirangu in teaching farmers how to computerize their records in the AgShare project.

Gidraph Nduati is an assistant professor of marketing and his specialty areas are research projects, internship, and marketing in the Chandaria School of Business. He has been involved in the AgShare project, where he taught Mwalimu Njuguna about the entrepreneurial mindset, and he is happy to report that Mwalimu Njuguna now keeps records.

Dalton Ndirangu is a professor of Computer Science at the National University of Science and Technology, and his specialty area is software engineering. He worked together with Professor Walter Wanyama in teaching farmers how to computerize their records in the AgShare project. 